\title{
Differences in maturity, morphological and physical attributes between players selected to the primary and secondary teams of a Portuguese Basketball elite academy
}

Sérgio Ramos, Anna Volossovitch, António Paulo Ferreira, Isabel Fragoso \& Luís Massuça

To cite this article: Sérgio Ramos, Anna Volossovitch, António Paulo Ferreira, Isabel Fragoso \& Luís Massuça (2019): Differences in maturity, morphological and physical attributes between players selected to the primary and secondary teams of a Portuguese Basketball elite academy, Journal of Sports Sciences, DOI: 10.1080/02640414.2019.1585410

To link to this article: https://doi.org/10.1080/02640414.2019.1585410

Published online: 01 Mar 2019.

Submit your article to this journal

View Crossmark data \lceil 


\title{
Differences in maturity, morphological and physical attributes between players selected to the primary and secondary teams of a Portuguese Basketball elite academy
}

\author{
Sérgio Ramos (10), Anna Volossovitch ${ }^{\mathrm{b}}$, António Paulo Ferreira ${ }^{\mathrm{b}}$, Isabel Fragoso ${ }^{\mathrm{b}}$ and Luís Massuça (1) ${ }^{\mathrm{a}, \mathrm{b}, \mathrm{c}}$ \\ ${ }^{a}$ Faculty of Physical Education and Sport, Universidade Lusófona, Lisbon, Portugal; bCIPER, Faculty of Human Kinetics, Universidade de Lisboa, Cruz- \\ Quebrada, Portugal; ICPOL, Higher Institute of Police Sciences and Internal Security, Lisbon, Portugal
}

ABSTRACT

The present study aims (i) to compare the maturational, morphological and fitness attributes of young basketball players of primary and secondary teams of an elite basketball academy, and (ii) to identify the set of morphological and fitness attributes which better discriminate the players from the two teams. A total of 116 male basketball players of an elite basketball academy were divided into primary (team A) and secondary (team B) teams in two age groups (U-14 and U-16). All the players were evaluated during two consecutive seasons and data related to players' practice experience, maturational, morphological and fitness attributes were collected at the beginning of the competition period. The results of the study suggest that: (i) in both age categories, team A players were older, more mature, bigger in size and had greater fitness profiles than team B players; (ii) stature and abdominal resistance were identified as discriminant attributes for youth basketball player performance; (iii) aerobic capacity for U-14 and agility for U-16 were identified as specific discriminant attributes for performance in youth basketball. Coaches are recommended to avoid premature talent identification and provide players with opportunities to progress through the talent pathway, at least until U-16 age category.
ARTICLE HISTORY

Accepted 29 January 2019

\section{KEYWORDS}

Team sports; physical fitness; morphology; skeletal age; talent identification

\section{Introduction}

Recent literature on youth sport has expanded from talent identification to talent development (Güllich, 2014; Vaeyens, Lenoir, Williams, \& Philippaerts, 2008). Talent identification refers to the process of recognizing current participants with the potential to become elite players, while talent development implies providing the most learning environment, so players have the opportunity to realize their potential (Vaeyens et al., 2008). This emphasis raised a relevant problem of categorization of young athletes in different stages of their long-term sports career and highlighted the need to examine the differences between levels of performance and how those differences evolve over time (Elferink-Gemser, Visscher, Lemmink, \& Mulder, 2007). Thus, for proper organization of the talent selection and development programs in basketball, it is important to identify a set of attributes associated to success of basketball players of different age groups.

Basketball is a dynamic and complex team sport which combines explosive movement structures, such as short sprints, abrupt stops, fast changes in direction, acceleration and vertical jumps (Erčulj, Blas, \& Bračič, 2010). In addition to technical/tactical skills (Trninić \& Dizdar, 2000) and psychological factors (Phillips, Davids, Renshaw, \& Portus, 2010), game performance in basketball is also influenced by players' anthropometric characteristics (e.g., stature, body mass and arm span), body composition (Ostojic, Mazic, \& Dikic, 2006) and fitness attributes (Drinkwater, Pyne, \& Mckenna, 2008). The determinants of competitive success vary across different age groups (Ibanez, Mazo, Nascimento, \& Garcia-Rubio, 2018; Rubajczyk, Swierzko, $\&$ Rokita, 2017). The majority of talent identification and selection programs are conducted during adolescence (Vaeyens et al., 2008). This developmental stage is characterized by great biological transformations, which can confound prediction of future performances (Pearson, Naughton, \& Torode, 2006; Vaeyens et al., 2008). In this period, young athletes with the same chronological age and who are competing in the same age group may present different biological development levels (Balyi \& Hamilton, 2004; Lloyd, Oliver, Faigenbaum, Myer, \& De Ste Croix, 2014). This may lead to advantages for early maturing athletes compared to late maturing athletes (Malina, Bouchard, \& Bar-Or, 2004). The differences in morphological and fitness attributes between early and late maturers are most evident during their fastest period of growth, known as the growth spurt. For male athletes, this stage normally corresponds to ages between 12 and 15 years (Philippaerts et al., 2006).

Portuguese youth basketball teams adopt a 2-year cohorts, and maturational differences between individuals of the same category tend to be reinforced by the fact that some players are born in the first months of the first semester (i.e., period of six months) and others, almost two years later, in the last months of the fourth semester (Steingrover, Wattie, Baker, Helsen, \& Schorer, 2017).

The difference in age between children born in the same year (one year cohorts) and their performance and 
participation consequences (regardless of whether they are relatively younger or older) are known as "relative age effects" (Barnsley \& Thompson, 1988; Musch \& Grondin, 2001). This phenomenon was observed in basketball (Delorme \& Raspaud, 2009; Torres-Unda et al., 2016) and other team sports (Helsen et al., 2012; Schorer, Wattie, \& Baker, 2013; Till et al., 2010).

Although considerable amount of research has been carried out to identifying differences between playing status or age groups, much less attention has been paid to the youth selection process at a local (academy) level (Johnston, Wattie, Schorer, \& Baker, 2018). Thus, the study of how the biological maturity, morphological and fitness attributes of young basketball players influence their selection process at a top elite academy may positively contribute to the literature. Therefore, the purposes of this study were: (i) to compare the maturational, morphological and fitness attributes of U-14 and U-16 basketball players who integrated the first team (team A) and the secondary team (team B), and (ii) to identify the set of morphological and fitness attributes differentiating team A from team B players.

\section{Methods}

\section{Subjects}

A total of 116 young male basketball players of two age categories Under-14 (U-14) and the Under-16 (U-16) participated in the study. The chronological age of players ranged between 12 and 15 years. All the players were included in the Basketball Players Training Program developed by the Sport Lisboa e Benfica - Elite Basketball Academy (SLB-EBA). The SLB-EBA is a SLB basketball organization, especially dedicated to the development of youth basketball training programs. Every season, players of each age category of SLB-EBA are involved in the talent identification and development program and are assigned one of two teams. The first team is known as the "primary team" or "team A", which is comprised of athletes who are considered the "best players" in the age group. The "secondary team", also known as the "team B", is comprised of the players who were not selected from to the "team A". The primary team participates in the National Championships of U-14 or U-16 categories, organized by Portuguese Basketball Federation; and secondary team participates in the U-14 or U-16 Lisbon Regional Championships organized by Lisbon Basketball Association.

Because Portuguese youth basketball adopts a 2-year cohorts, the date of birth of the participants in the same age group was divided in 4 semesters accordingly: S1, January $1-$ June 31 (second year in the age category); S2, July 1 December 31 (second year in the age category); S3, January 1 - June 31 (first year in the age category); and S4, July 1 - December 31 (first year in the age category). All the athletes of the same age group underwent the same training program per week: U-14 players had 4 training sessions and 360 minutes of practice; and U-16 players had 5 training sessions and 450 minutes of practice. Data related to players' maturational, morphological and fitness characteristics were collected at the beginning of the competition period (November) in two consecutive seasons. A total of 26 players from team A and 29 players from team B of U-14 category, and 32 from team $A$ and 29 players from team B of U-16 category were assessed.

All the participants received a clear explanation of aims and procedures of the study. Only the players whose parents or legal guardians had signed an informed consent form were permitted to participate in the study. The study was authorized by the Ethics Committee of the Faculty of Physical Education and Sport - Universidade Lusófona and performed according to the Helsinki declaration.

\section{Procedures}

The evaluation protocol used in the study examined maturational, morphological, and fitness evaluations.

\section{Age and maturity}

Chronological age ( $C A$; in decimals) was calculated as the difference between the date on which the anthropometric measures were taken and the date of birth. Skeletal age (SA) was considered to determine biological maturity, which was obtained through radiographs of left wrist. Thirteen bones were evaluated by comparing the ossification phase of each bone with a radiographic atlas according to the TannerWhitehouse Method III - TW3 method (Tanner, Healy, Goldstein, \& Cameron, 2001). The x-ray was performed in one session, and its effective radiation dose was estimated between 3 and 5-millirem (0003-0007 rads), representing approximately $5 \%$ of an allowable annual dose. One very skilled technician who has read more than $4000 \mathrm{X}$-rays using this method evaluated the SA of each participant blinded to participants' chronological age. Every six months this technician compares his readings with the readings of an expert (one of the authors of the TW III Method) and an inter examiner reliability was calculated (ICC: $0.86-0.98$ ).

\section{Morphological evaluations}

Body mass, stature, arm span, and three skinfolds (triceps, TRI; calf, GML; and subscapular, SBS) were measured following the International Society for the Advancement of Kinanthropometry (ISAK) protocol (Marfell-Jones, Olds, Stewart, \& Carter, 2006). Arm span was measured as a perpendicular distance between the longitudinal planes of the left and right dactylion, while hand span was measured as the greater distance between the longitudinal planes of the first and fifth fingers (Massuça \& Fragoso, 2013). Body mass was measured, to the nearest $0.5-\mathrm{kg}$, using a scale (Secca model 761 7019009, Vogel \& Halke, Germany) and stature was measured to the nearest $\mathrm{mm}(0.1-\mathrm{cm})$ using a SiberHegner anthropometric kit (DKSH Ltd., Zurich, Switzerland). The three skinfolds were measured using a Rosscraft Slim Guide Skinfold (2001) caliper, which allows reading of millimeters up to the $10^{\text {th }}$ (at a pressure on the tips of $10-\mathrm{mg} / \mathrm{cm}^{2}$ ). All measures were taken by two certified ISAK anthropometric technicians in a private and heated room within medical facilities. Individual measurements of all subjects were collected by the same ISAK evaluators (Intra-observer technical error of measurements (TEM): stature, $R \geq 0.98$; skinfolds, between $\mathrm{R}=[0.92-0.98])$. 
The body composition analysis included evaluation of fat mass (Hoffman, Tenenbaum, Maresh, \& Kreamer), free-fat mass (Hoffman et al.) and body mass index (BMI) (Frisancho, 2008). The relative FM (\%FM) and the FFM $(\mathrm{kg})$ were estimated from the value of skinfolds. The \%FM was calculated as the arithmetic mean of the \%FM values obtained through the equations proposed by Lohman (Equation 1: \% $\mathrm{FM}=1.35 \times(\mathrm{TRI}+\mathrm{SBS})-0012 \times(\mathrm{TRI}+\mathrm{SBS})^{2}-\mathrm{I}$, and $\mathrm{I}=$ constant) (Lohman, 1986) and Slaughter and colleagues (Equation 2: \%FM $=0.735 \times(\mathrm{TRI}+\mathrm{GML})+1$ ) (Slaughter et al., 1988). BMI was calculated by the formula BMI = Body mass/ Stature $^{2}\left(\mathrm{Kg} / \mathrm{m}^{2}\right)$.

\section{Fitness evaluation}

Before the fitness tests all the participants performed a 20-min standardized warm-up routine (a slow jogging followed by static and dynamic stretching). The test's order was not fixed, except for the line drill test and the Yo-Yo intermittent recovery test, which were always performed last to avoid the influence of fatigue in the results of other tests. The players were allowed a 10-min passive rest between tests, as well as water breaks and extra rest time. Each participant was verbally instructed and encouraged to give his/her maximal effort. All players completed eight fitness tests, from which nine variables were collected for analysis.

Speed test. The 20-m speed test was performed according to the protocol described by Jakovljevic and colleagues (Jakovljevic, Karalejic, Pajic, Macura, \& Erculz, 2012) and consisted of a 20-m race. All participants departed from a standing position. The time of speed test was recorded in seconds and hundredths of second using photoelectric cells (Wireless Sprint system, Brower Timing Systems, Salt Lake City, Utah USA). The best time of two attempts was registered. The intraclass correlation coefficient (ICC) for the speed test was $r=0.937(p<0.001)$.

T-Test. T-test was used for the agility assessment (Delextrat \& Cohen, 2009; Jakovljevic et al., 2012). When performing the test, participants started from the standing position at the final line of the basketball court, sprinted 9.15-m in straight line touching the cone $A$, slipped into defensive position and touched the cone $B$ that was $4.55-\mathrm{m}$ away to the left from cone $A$, slid defensively to cone $C$, which was at $4.55-\mathrm{m}$ distance to the right of the cone $A(9.10-m$ from cone $B)$, defensively slid back to the cone $A$, which was at $4.55-\mathrm{m}$ from cone $C$ and ran backward to the starting line (Jakovljevic et al., 2012). The time of T-test test was recorded in seconds and hundredths of second using photoelectric cells (Wireless Sprint system, Brower Timing Systems, Salt Lake City, Utah USA). The best time of two attempts was registered. The ICC for the T-test was $r=0.962(p<0.001)$.

Vertical jump test. The explosive and elastic leg strength were tested in the squat jump (SJ) and counter movement jumps (CMJ), following the protocol described by Bosco and co-authors (Bosco, Luhtanen, \& Komi, 1983). The height (centimeters, cm) and power (Watts, W) of vertical jumps were recorded with a Chronojump measurement technology (Bosco System, Globus, Italy). The best record of two attempts was recorded. In both tests, the retry interval was $10-$ s. For the SJ the participant initiated from a squatting position - first performing a crouching action followed immediately by a jump to maximal height (Bosco et al., 1983). For the CMJ the participant was allowed a downward movement by rapidly bending and extending his knees to jump as high as possible. During the CMJ the participant maintained his trunk in an upright posture and their hands on hips to eliminate the influence of arm swing. The ICC for height and power of SJ test were $r=0.986(p<0.001)$ and $r=0.996(p<0.001)$, respectively. The ICC for height and power of CMJ test were $r=0.976(p<0.001)$ and $r=0.994(p<0.001)$, respectively.

2-kg medicine ball throw. The upper-limb explosive strength was tested using the medicine ball throw (MBT). Participants started the test from a sitting position with the back against the wall using a release from the chest. The distance $(\mathrm{cm})$ attained in the best of two attempts was recorded. MBT was used in similar studies to measure the explosive upper body strength (Delextrat \& Cohen, 2009; Santos \& Janeira, 2008). The ICC for the 2-kg MBT test was $r=0.982(p<0.001)$.

Handgrip strength. The handgrip (HG) strength was assessed with a dynamometer (Takei Physical Fitness Test, TKK 5001, GRIP - A). Participants performed the test twice with each hand, and the sum of best results achieved by left and right hand was recorded (in $\mathrm{kg}$ ). The ICC for the right and left handgrip test were $r=0.990(p<0.001)$ and $r=0.989$ ( $p<0.001)$, respectively.

Abdominal strength. An athlete's abdominal strength was assessed using the 60-seconds sit-up test (Semenick, 1994). The participants completed one trial and the number of repetitions was recorded.

Aerobic capacity. The Yo-Yo intermittent recovery test, level 1 (YYIR1) was used to assess players' aerobic capacity (BenAbdelkrim, Chaouachi, Chamari, Chtara, \& Castagna, 2010; Castagna, Impellizzeri, Rampinini, D'Ottavio, \& Manzi, 2008). The YYIR1 consists of two times 20-m progressive speed sprints interspersed with 10-s active recovery, performed until exhaustion after pre-recorded acoustic signals (Bangsbo, 1994). From the results of YYIR1, the maximal oxygen uptake ( $\dot{V}_{2}$ max) was estimated by applying the equation proposed by Bangsbo and colleagues (Bangsbo, laia, \& Krustrup, 2008) based on the distance covered by athletes $\left(\dot{\boldsymbol{V}} \mathrm{O}_{2} \max (\mathrm{ml} / \mathrm{kg} /\right.$ min) YYIR1 = (distance; in $\mathrm{m}) \times 0.0084+36.4)$.

Anaerobic capacity. The Line Drill (LD) test was used to assess anaerobic capacity (Carvalho et al., 2011). Subjects ran $140-\mathrm{m}$ as quickly as possible in the form of four consecutive round trip sprints of $5.8-\mathrm{m}, 14.0-\mathrm{m}, 22.2-\mathrm{m}$ and $28.0-\mathrm{m}$ in basketball court. Athletes started the test one meter behind the basketball court bottom line. The time was recorded by photoelectric cells (Wireless Sprint System, Brower Timing Systems, Salt Lake City, Utah USA) placed at the bottom line where athletes change direction after the one-way sprint trip.

\section{Statistical analysis}

All the analyses were performed using the Statistical Package for the Social Sciences software (SPSS version 22.0, IBM SPSS, Chicago, IL), and the significance was set at $5 \%$ with effect sizes (Cohen's $d$ ) also calculated.

Exploratory data analysis was conducted for birth dates distribution. The descriptive data are presented as means 
and standard deviations $(\mathrm{M} \pm \mathrm{SD})$. After normality and homogeneity of variances inspection (Shapiro-Wilk test and the Levene test, respectively) a corrective mathematical transformation was applied, where necessary.

The significant differences among the average maturity, morphologic and fitness variables between team $A$ and team B of U-14 and U-16 age groups were evaluated using Student $t$-test for independent samples. An analysis of covariance (ANCOVA) with Bonferroni adjustment was conducted to evaluate the effect of biological maturity on morphological and fitness attributes (SA has been used as the confounding variable). The variables, for which significant differences have been identified between groups, were used in the Stepwise Discriminant Function Analysis to determine what set of variables discriminated team $A$ from team $B$ players (in U-14 and $\mathrm{U}-16$ age groups). The assumption of equality of the group covariance matrices was checked by Box's M test (Carter, Ackland, Kerr, \& Stapff, 2005).

\section{Results}

In U-14 category, the majority of team A players were born in the first $(35.7 \%)$ and second (25.9\%) semester while team B players in the fourth semester (37\%) (see Figure 1). In addition, team A players were, on average, older ( +0.4 years), more mature (+1.19 years), and had superior body size measurements and superior performance in all analysed fitness attributes compared to team B players. Significant differences were observed (all in favour of team $A)$ in maturity (SA; $\mathrm{p}=0.011, d=0.71)$, stature $(\mathrm{p}=0.004, d=0.82)$, arm span $(\mathrm{p}=0.026, d=0.62)$, lean mass $(\mathrm{p}=0.025, d=0.60)$, speed ( $\mathrm{p}=0.044, d=0.54)$, agility $(\mathrm{p}<0.001$, $d=1.04)$, abdominal resistance $(\mathrm{p}=0.001, d=0.97)$, upper-body strength (MBT, $\mathrm{p}=0.005, d=0.79)$, aerobic $(\mathrm{p}=0.002, d=0.87$ ) and anaerobic $(\mathrm{p}=0.001, d=0.97)$ capacities. When maturity was considered, significant differences remain in agility, abdominal resistance, and aerobic capacity and anaerobic capacity (Table 1). Discriminant analysis showed that the combination of stature (coefficient: 0.692), abdominal resistance (coefficient: 0.604) and aerobic capacity (coefficient: 0.604$)$ successfully discriminated team A from team B players $\left(\Lambda=0.580, X^{2}(2)=28.078\right.$, $p<0.001$; correct classification, $78.2 \%$; Table 2 ).

In U-16 category, team A players were born mostly in the first $(39.3 \%)$ and second (35.7\%) semester while team B players did it in the third (35.5\%) and fourth semester (38.7\%) (see Figure 1). In addition, team A players were, on average, older (+0.53 years), more mature (+0.82 years), and demonstrated superior performance in all fitness evaluations than team B players. Significant differences were observed in chronological age $(p<0.001$, $d=1.11)$, skeletal age $(\mathrm{p}=0.004, d=0.79)$, body mass $(\mathrm{p}<0.001$, $d=1.01)$, stature $(\mathrm{p}<0.001, d=1.26)$, arm span $(\mathrm{p}<0.001, d=1.08)$, lean mass ( $p=0.001, d=1.29)$, agility $(\mathrm{p}<0.001, d=1.07)$, lowerlimb power (SJ, $\mathrm{p}<0.001, d=1.19$; CMJ, $\mathrm{p}<0.001, d=1.16$ ), abdominal resistance ( $p=0.040, d=0.55)$, upper-body strength (MBT, $\mathrm{p}<0.001, d=1.18 ; \mathrm{HG}, \mathrm{p}=0.023, d=0.61$ ) and anaerobic capacity ( $p=0.004, d=0.75$ ). When the effect of maturity was statistically removed and with exception of the squat jump power and handgrip strength, most of the previously observed differences remained (Table 1). Discriminant analysis showed that the combination of stature (coefficient: 0.963), agility (coefficient: -0.652 ) and abdominal resistance (coefficient: 0.451 ) successfully discriminated team A from team B players $\left(\Lambda=0.455, X^{2}\right.$ (2) = 42.932, $p<0.001$; correct classification, 89.8\%; Table 2).

\section{Discussion}

The results of the present study suggest that (i) team A players are older, more mature, bigger in size and have greater fitness profiles than the team B players; (ii) stature and abdominal resistance correctly distinguished the best players from others in both categories: U-14 and U-16; (iii) aerobic capacity discriminates youth basketball players according to their level in $\mathrm{U}-14$, and agility in U-16 category; and (iv) biological maturation (SA) had an effect on the reported discriminant attributes in the stature of U-14 category.

Traditionally, stature is considered an important variable in basketball performance at youth level (Karpowicz, 2006; Torres-Unda et al., 2013, 2016). Our first analysis showed that players from team $A$ were significantly taller than players from team B in the U14 category by $9.2 \mathrm{~cm}$ and by $13.4 \mathrm{~cm}$ in the U16 category. This observation, together with the results of the discriminants analysis, helps to reiterate the importance of stature as a key factor for talent selection in youth basketball.

Although playing positions were not considered in the present study, it is worth mentioning that U-16 players are at the beginning of the specialization stage of the long-term athlete development framework (Côté, Horton, MacDonald, \& Wilkes, 2009). In this stage they usually choose their specific playing positions. Ostojic and colleagues reported that stature
U14

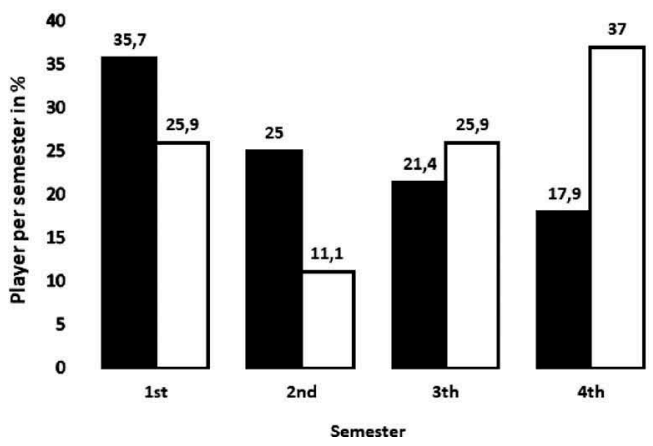

U16

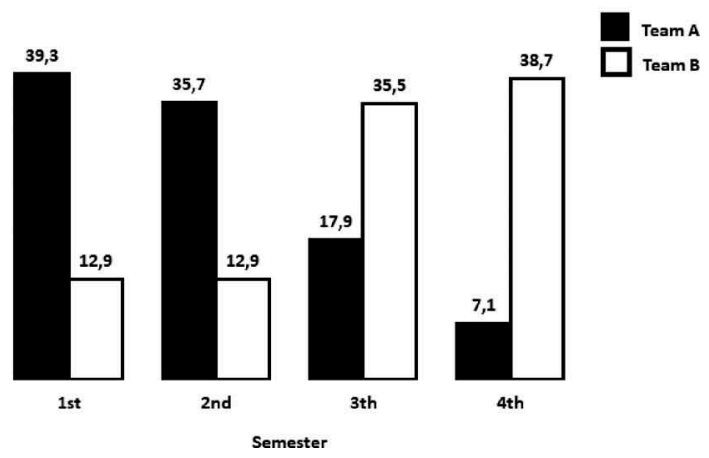

Figure 1. Distribution of players'birth semesters of Team A and Team B players in U-14 and U-16 categories. 


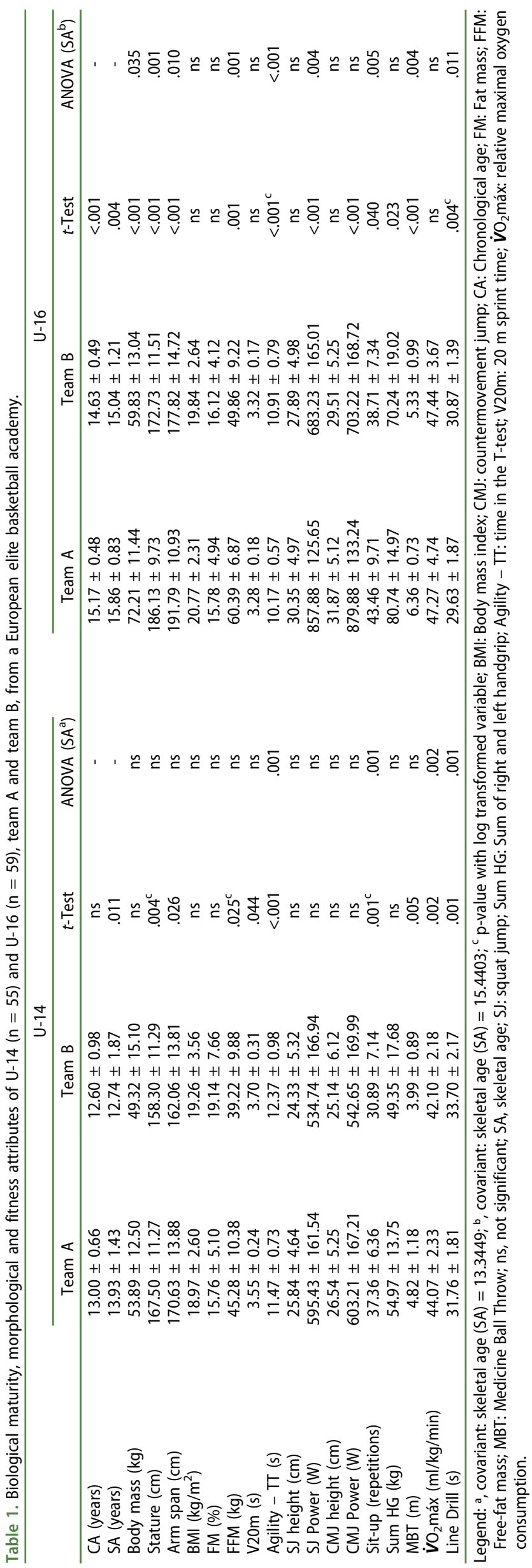


Table 2. Summary of standardized canonical discriminant function coefficients, eigenvalues, variance and correct classification cases in U-14 and U-16 selection processes from a European elite basketball academy.

\begin{tabular}{lcc}
\hline & U-14 & U-16 \\
\hline Stature (cm) & 0.692 & 0.963 \\
Agility - TT (s) & - & -0.652 \\
Sit-up (repetitions) & 0.604 & 0.451 \\
$\dot{\boldsymbol{V}} \mathrm{O}_{2}$ max (ml/kg/min) & 0.604 & - \\
Eigenvalue & 0.725 & 1.198 \\
Cases correctly classified (\%) & 78.2 & 89.8 \\
Function & $\wedge=0.580$ & $\wedge=0.455$ \\
& $\mathrm{X} 2(2)=28.078$ & $\mathrm{X} 2(2)=42.932$ \\
& $\mathrm{p}<0.001$ & $\mathrm{p}<0.001$ \\
\hline
\end{tabular}

was a key variable at the professional level of basketball and also mentioned that the stature of players of all basketball playing positions has been increasing over time (Ostojic et al., 2006). Therefore, it is proposed that the selection process in youth basketball tends to express this trend, similar in all playing position, highlighting the coaches' concern in selecting athletes that can fit elite' basketball profile, characterized by a high stature.

Body size differences are often related with advanced physical maturity and also RAE.

Literature suggests that RAE can be explained by advanced physical maturity of older players and, consequently, bigger body size, which provides an advantage in the player's performance (Fragoso, Massuca, \& Ferreira, 2015; Helsen et al., 2012). The results of the present study confirmed the overrepresentation of players born in the second year of the age category (i.e., first and second semesters) in both age categories, thereby confirming the presence of RAE in the player's selection process. In fact, almost $61 \%(\mathrm{U}-14)$ and $65,1 \%(\mathrm{U}-16)$ of team $\mathrm{A}$ players were born in the first and second semesters. Further, almost $63 \%$ $(\mathrm{U}-14)$ and $74,2 \%(\mathrm{U}-16)$ of team B players were born in the third and fourth semesters. Previous studies observed this tendency in basketball (Delorme \& Raspaud, 2009; Torres-Unda et al., 2013), soccer (Helsen et al., 2012), handball (Aguilar, Garcia, \& Romero, 2017; Gomez-Lopez, Sanchez, Granero-Gallegos, \& Rios, 2017), rugby (Till et al., 2010), and ice hockey (Sherar, Baxter-Jones, Faulkner, \& Russell, 2007).

The finding that abdominal resistance was identified as a significant discriminating attribute for the level of performance of U14 and U16 players is not in accordance with the findings of Hoare (2000). The author of this study did not find significant differences in the seven stage multi-level abdominal test between U16 basketball players with different level of performance (Hoare, 2000). In fact, the test used in the present study and the one used in Hoare (2000), to evaluate abdominal strength, have different protocols, which does not help the comparison of results.

The occurrence of numerous situations requiring multiple and rapid changes of direction in a small space field, could explain the relevance of agility in basketball (Jakovljevic et al., 2012). A previous study with $125 \mathrm{U}-16$ male basketball players observed that players with better playing performances had, on average, better agility performances than the rest of players in all specific positions (i.e., point guard, off guard, small forward, power forward and centre) (Hoare, 2000). Recent research also highlighted agility as an important attribute for the performance of young basketball teams. U-14 male players from higher-ranked teams have been reported to be more agile than players from lower-ranked teams (Ramos et al., 2018). The results of the present study are in line with these findings, suggesting agility is a fundamental attribute for the performance in youth basketball.

Discriminant analysis also revealed that aerobic capacity can be considered a distinguishing attribute for the selection process of U-14 basketball players. Previous studies demonstrated how aerobic fitness contributes to improving of basketball performance (Ben Abdelkrim, El Fazaa, \& El Ati, 2007; Castagna et al., 2008) (i) by generating and maintaining power output during repeated sprints or high-intensity accelerations with short recovery intervals (Meckel, Gottlieb, \& Eliakim, 2009) and (ii) by enhancing the ability to recover from the anaerobic efforts during a game (Tomlin \& Wenger, 2001). In addition, other researchers reported that elite junior basketball players had higher aerobic performances than their lower-level counterparts (Drinkwater et al., 2008; Vernillo, Silvestri, \& La-Torre, 2012).

Significant differences in skeletal age, which were identified between team A and team B players in both age categories, help shed light on the influence of biological maturation on the selection process in youth basketball. Coelho e Silva, Figueiredo, Gonçalves, Vaz, and Malina (2004) also reported that majority of basketball players selected for the Portuguese Junior National team (aged from 15 to 16 years) had advanced maturation status and none of the players was a late maturing athlete (Coelho e Silva et al., 2004). The same authors noted that the selection process in basketball U-16 category favours individuals with superior body size and with a more advanced biological development. The finding that team A players were taller and more mature than their team $B$ counterparts suggests that players may be selected to team $A$ as a product of their physical advantage. These findings are in line with conclusions of numerous studies conducted with young players of roller hockey (Coelho e Silva et al., 2012; Figueiredo, Coelhoe-Silva, Cummings, \& Malina, 2010; Matthys, Vaeyens, Coelho e Silva, Lenoir, \& Philippaerts, 2012; Torres-Unda et al., 2013).

The variability of maturation processes may lead to different biological development levels of youth basketball players of the same chronological age (Balyi \& Hamilton, 2004), which results in a higher fitness performance, especially in tasks that require speed, agility, explosive strength, and muscular endurance (Malina et al., 2004). In a sport like basketball, where body size and strength have a decisive role in performance (Karpowicz, 2006; Ostojic et al., 2006), the physical advantages contribute to the superior athletic performance and, consequently, may increase the likelihood of being selected for the team A.

The findings of present study suggest that maturation status may be related to morphological and fitness attributes (Table 1). The effect of maturation is more pronounced in U-14 category than in U-16 category (i.e., in U-14 category all the morphological differences related to the selected groups disappeared when the skeletal age effect was statistically controlled).

Consistent with the findings of our study for U-14 category, Coelho e Silva et al. (2010) found that maturity status of young basketball players (aged from 12.0 to 13.9 years-old) explained a significant portion of variance in body size and had a significant effect for upper-limb strength (Coelho e Silva et al., 2010). The same authors also mentioned that maturity status did not influence sit-ups or aerobic endurance, which has been observed in 
the present study. Our results illuminate that, with exception of stature in U-14 category, the biological maturity does not have a statistically significant result on the selected U-14 and U-16 discriminant attributes, such as agility, abdominal resistance, aerobic capacity and stature in U-16 category.

It is important to mention that in the $\mathrm{U}-16$ age category, the observed differences between team $A$ and team B players for stature and agility were not explained only by maturation status, but also by the players individual characteristics and level of physical fitness.

Finally, the set of identified attributes discriminating the team A from team B players in youth basketball (U-14 and $\mathrm{U}-16)$ are in line with previous studies highlighting body size and muscle strength as key attributes for basketball performance (Karpowicz, 2006; Ostojic et al., 2006), which may play a large role in the selection process of the elite basketball teams (Coelho e Silva et al., 2004; Torres-Unda et al., 2013).

The present study focuses on physical fitness and maturation variables. This two-dimensional approach, while valid, is still reductive because does not reflect the multidimensionality of sport success and can be considered as the main limitation of this study. Thus, future research should consider to use more holistic approaches (Johnston et al., 2018; Massuça, Fragoso, \& Teles, 2014; Vaeyens et al., 2008) that include in the talent identification and development programs the analysis of other important factors, such as psychological, technical and tactical. This study was conducted through two seasons. To identify the potential similarities or differences with selections through different recruitment classes in the future studies it would be useful to consider multiple seasons comparisons. A longitudinal study may help provide a more robust understanding of the discriminating factors that emerge through selections and throughout age cohorts. Our work shed light only on the male basketball young athlete demographic, further research should focus on the selection process in the youth female basketball. It should also be mentioned that in the U-14 group, $78.2 \%$ of players were correctly classified. This means that more than $20 \%$ of athletes were selected based on some other factor (or combinations of factors) that may affect the selection. This finding has social consequences as there may be false negatives and false positives happening during selection of young basketball players. This assumption highlights the importance to focus on talent development programs instead of early talent identification and selection, which are based on biological determinants and genetic factors. The initial stages of selection, conducted in the clubs, may have a decisive influence on the sports training process of young players. Athletes selected for the first team often have access to better practice conditions (i.e., better coaches, higher level of internal competition, better organized and demanding practice), crucial for their talent development. Thus, coaches are recommended to provide all young players with opportunities to progress into the talent pathway, rather than prematurely exclude those who do not fit into the models, at least until U-16 age category.
Despite the above-mentioned limitations, the study of differences between team $A$ and team $B$ male basketball players at the U-14 and U-16 level contribute to the understanding of factors influencing selection and player performance in those cohorts.

\section{Disclosure statement}

No potential conflict of interest was reported by the authors.

\section{ORCID}

Sérgio Ramos (D) http://orcid.org/0000-0001-9061-3027 Luís Massuça (iD) http://orcid.org/0000-0001-8786-3498

\section{References}

Aguilar, O. G., Garcia, M. S., \& Romero, J. J. F. (2017). Constituent year effect in international handball at high level. Journal of Human Sport and Exercise, 12(2), 316-324.

Balyi, I., \& Hamilton, A. (2004). Long-term athlete development: Trainability in childhood and adolescence. Windows of opportunity. Optimal trainability. Victoria: National Coaching Institute British Columbia \& Advanced Training and Performance Ltd.

Bangsbo, J. (1994). Fitness training in Football: A scientific approach. Copenhagen: August Krogh Institute, University of Copenhagen.

Bangsbo, J., laia, F., \& Krustrup, P. (2008). The Yo-Yo intermittent recovery test: A useful tool for evaluation of physical performance in intermittent sports. Sports Medicine, 38(1), 1-15.

Barnsley, R. H., \& Thompson, A. H. (1988). Birthdate and success in minor hockey - the key to the NHL. Canadian Journal of Behavioural ScienceRevue Canadienne Des Sciences Du Comportement, 20(2), 167-176.

Ben Abdelkrim, N., El Fazaa, S., \& El Ati, J. (2007). Time-motion analysis and physiological data of elite under-19-year-old basketball players during competition. British Journal of Sports Medicine, 41, 69-75.

Ben-Abdelkrim, N., Chaouachi, A., Chamari, K., Chtara, M., \& Castagna, C. (2010). Positional role and competitive-level differences in elite-level men's basketball players. Journal of Strength and Conditioning Research, 24(5), 1346-1355.

Bosco, C., Luhtanen, P., \& Komi, P. (1983). A simple method for measurement of mechanical power in jumping. European Journal Applied Physiology, 50(2), 273-282.

Carter, J. E. L., Ackland, T. R., Kerr, D. A., \& Stapff, A. B. (2005). Somatotype and size of elite female basketball players. Journal of Sports Sciences, 23 (10), 1057-1063.

Carvalho, H., Coelho-e-Silva, M., Figueiredo, A., Gonçalves, C., Castagna, C., Philippaerts, R., \& Malina, R. (2011). Cross-validation and reliability of the line-drill test of anaerobic performance in basketball players 14-16 years. Journal of Strength and Conditioning Research, 25(4), 1113-1119.

Castagna, C., Impellizzeri, F., Rampinini, E., D'Ottavio, S., \& Manzi, V. (2008). The yo-yo intermittent recovery test in basketball players. Journal of Science and Medicine in Sport, 11, 202-208.

Coelho e Silva, M., Carvalho, H., Gonçalves, C., Figueiredo, A., ElferinkGemser, M., Philippaerts, R., \& Malina, R. (2010). Growth, maturation, functional capacities and sport-specific skills in 12-13-year-old basketball players. Journal of Sports Medicine and Physical Fitness, 50(2), 174-181.

Coelho e Silva, M., Figueiredo, A., Gonçalves, C., Vaz, V., \& Malina, R. (2004). Crescimento, maturação e performance no contexto da formação desportiva. Revista Portuguesa de Ciências do Desporto, 4, 91-94.

Coelho e Silva, M., Vaz, V., Simões, F., Carvalho, H., Valente Dos Santos, J., Figueiredo, A., ... Malina, R. (2012). Sport selection in under-17 male roller hockey. Journal of Sports Sciences, 30(6), 1793-1802. 
Côté, J., Horton, S., MacDonald, D., \& Wilkes, S. (2009). The benefits of sampling sports during childhood. Physical and Health Education Journal, 74(4), 6-11.

Delextrat, A., \& Cohen, D. (2009). Strength, power speed and agility of women basketball players according to playing position. Journal of Strength and Conditioning Research, 23(7), 1974-1981.

Delorme, N., \& Raspaud, M. (2009). The relative age effect in young French basketball players: A study on the whole population. Scandinavian Journal of Medicine \& Science in Sports, 19(2), 235-242.

Drinkwater, E., Pyne, D., \& Mckenna, M. (2008). Design and interpretation of anthropometric and fitness testing of basketball players. Sports Medicine, 38(7), 565-578.

Elferink-Gemser, M. T., Visscher, C., Lemmink, K., \& Mulder, T. (2007). Multidimensional performance characteristics and standard of performance in talented youth field hockey players: A longitudinal study. Journal of Sports Sciences, 25, 481-489.

Erčulj, F., Blas, M., \& Bračič, M. (2010). Physical demands on young elite European female basketball players with special reference to speed, agility, explosive strength, and take-off power. Journal of Strength and Conditioning Research, 24, 2970-2978.

Figueiredo, A., Coelho-e-Silva, M., Cummings, S., \& Malina, R. (2010). Size and maturity mismatch in youth soccer players 11 - to 14-years-old. Paediatric Exercise Science, 22, 596-612.

Fragoso, I., Massuca, L. M., \& Ferreira, J. (2015). Effect of birth month on physical fitness of soccer players (under-15) according to biological maturity. International Journal of Sports Medicine, 36(1), 16-21.

Frisancho, A. R. (2008). Anthropometric standards: An interactive nutritional reference of body size and body composition for children and adults (2nd ed.). Ann Arbor: University of Michigan Press.

Gomez-Lopez, M., Sanchez, S. A., Granero-Gallegos, A., \& Rios, L. J. C. (2017). Relative age effect in handball players of Murcia: Influence of sex and category of game. Journal of Human Sport and Exercise, 12(3), 565-573.

Güllich, A. (2014). Selection, de-selection and progression in German football talent promotion. European Journal of Sport Science, 14(6), 530-537.

Helsen, W. F., Baker, J., Michiels, S., Schorer, J., Van Winckel, J., \& Williams, A. M. (2012). The relative age effect in European professional soccer: Did ten years of research make any difference? Journal of Sports Sciences, 30(15), 1665-1671.

Hoare, D. (2000). Predicting success in junior elite basketball players the contribution of anthropometric and physiological attributes. Journal of Science and Medicine in Sport, 3, 391-405.

Ibanez, S. J., Mazo, A., Nascimento, J., \& Garcia-Rubio, J. (2018). The relative age effect in under-18 basketball: Effects on performance according to playing position. PLoS One, 13(7), 11.

Jakovljevic, S., Karalejic, M., Pajic, Z., Macura, M., \& Erculz, F. (2012). Speed and Agility of 12 and 14-year-old elite male basketball players. Journal of Strength and Conditioning Research, 26(9), 2453-2459.

Johnston, K., Wattie, N., Schorer, J., \& Baker, J. (2018). Talent identification in sport: A systematic review. Sports Medicine, 48(1), 97-109.

Karpowicz, K. (2006). Interrelation of selected factors determining the effectiveness of training in young basketball players. Human Movement, 7(2), 130-146.

Lloyd, R. S., Oliver, J. L., Faigenbaum, A. D., Myer, G. D., \& De Ste Croix, M. B. A. (2014). Chronological age vs. biological maturation: Implications for exercise programming in youth. Journal of Strength and Conditioning Research, 28(5), 1454-1464.

Lohman, T. G. (1986). Applicability of body composition techniques and constants for children and youths. Exercise Sports Sciences Reviews, 14, 325-357.

Malina, R. M., Bouchard, C., \& Bar-Or, O. (ed.). (2004). Growth, maturation and physical activity (2nd ed.). Champaign, IL: Human Kinetics.

Marfell-Jones, M., Olds, T., Stewart, A., \& Carter, J. (2006). International Standards for Anthropometric Assessment (revised 2006). Underdale, S. A.: International Society for the Advancement of Kinanthropometry.

Massuça, L., \& Fragoso, I. (2013). A multidisciplinary approach of success in team-handball. Apunts. Medicina de l'Esport, 48(180), 143-151.

Massuça, L., Fragoso, I., \& Teles, J. (2014). Attributes of top elite team-handball players. Journal of Strength and Conditioning Research, 28(1), 178-186.
Matthys, S., Vaeyens, R., Coelho e Silva, M., Lenoir, M., \& Philippaerts, R. (2012). The contribution of growth and maturation in the functional capacity and skill performance of male adolescent handball players. International Journal of Sports Medicine, 33(7), 543-549.

Meckel, Y., Gottlieb, R., \& Eliakim, A. (2009). Repeated sprint tests in young basketball players at different game stages. European Journal of Applied Physiology, 107, 273-279.

Musch, J., \& Grondin, S. (2001). Unequal competition as an impediment to personal development: A review of the relative age effect in sport. Developmental Review, 21(2), 147-167.

Ostojic, S., Mazic, S., \& Dikic, N. (2006). Profiling in basketball: Physical and physiological characteristics of elite players. Journal of Strength and Conditioning Research, 20(4), 640-744.

Pearson, D. T., Naughton, G. A., \& Torode, M. (2006). Predictability of physiological testing and the role of maturation in talent identification for adolescent team sports. Journal of Science and Medicine in Sport, 9 (4), 277-287.

Philippaerts, R., Vaeyens, R., Janssens, M., Van Renterghem, B., Matthys, D., Craen, R., ... Malina, R. (2006). The relationship between peak height velocity and physical performance in youth soccer players. Journal of Sports Sciences, 24(3), 221-230.

Phillips, E., Davids, K., Renshaw, I., \& Portus, M. (2010). Expert performance in sport and its dynamics of talent development. Sports Medicine, 40(4), 271-283.

Ramos, S., Volossovitch, A., Ferreira, A. P., Barrigas, C., Fragoso, I., \& Massuça, L. (2018). Differences in maturity, morphological, and fitness attributes between the better- and lower-ranked male and female U-14 Portuguese elite regional basketball teams. Journal of Strength and Conditioning Research, 1-10. doi:10.1519/ JSC.0000000000002691

Rubajczyk, K., Swierzko, K., \& Rokita, A. (2017). Doubly disadvantaged? The relative age effect in Poland's basketball players. Journal of Sports Science and Medicine, 16(2), 280-285.

Santos, E., \& Janeira, M. (2008). Effects of complex training on explosive strength in adolescent male basketball player. Journal of Strength and Conditioning Research, 22(3), 903-909.

Schorer, J., Wattie, N., \& Baker, J. R. (2013). A new dimension to relative age effects: Constant year effects in German youth handball. PLoS One, 8(4), 7.

Semenick, D. (1994). Testing protocols and procedures. In T. R. Baechle \& R. W. Earle (Eds.), Essentials of strength training and conditioning ( $\mathrm{pp}$. 258-273). Champaign, IL: Human Kinetics.

Sherar, L. B., Baxter-Jones, A. D. G., Faulkner, R. A., \& Russell, K. W. (2007). Do physical maturity and birth date predict talent in male youth ice hockey players? Journal of Sports Sciences, 25(8), 879-886.

Slaughter, M. H., Lohman, T. G., Boileau, R. A., Horswill, C. A., Stillman, R. J., Van Loan, M. D., \& Bemben, D. A. (1988). Skinfold equations for estimations of body fatness in children and youth. Human Biology, 60(5), 709-723.

Steingrover, C., Wattie, N., Baker, J., Helsen, W. F., \& Schorer, J. (2017). The interaction between constituent year and within-1-year effects in elite German youth basketball. Scandinavian Journal of Medicine \& Science in Sports, 27(6), 627-633.

Tanner, J., Healy, M., Goldstein, H., \& Cameron, C. (2001). Assessment of skeletal maturity and prediction of adult height (TW3 Method). London: W.B. Saunders.

Till, K., Cobley, S., Wattie, N., O'Hara, J., Cooke, C., \& Chapman, C. (2010). The prevalence, influential factors and mechanisms of relative age effects in UK Rugby League. Scandinavian Journal of Medicine \& Science in Sports, 20(2), 320-329.

Tomlin, D. L., \& Wenger, H. A. (2001). The relationship between aerobic fitness and recovery from high intensity intermittent exercise. Sports Medicine, 31, 1-11.

Torres-Unda, J., Zarrazquin, I., Gil, J., Ruiz, F., Irazusta, A., Kortajarena, M., ... Irazusta, J. (2013). Anthropometric, physiological and maturational characteristics in selected elite and non-elite male adolescent basketball players. Journal of Sports Sciences, 31(2), 196-203. 
Torres-Unda, J., Zarrazquin, I., Gravina, L., Zubero, J., Seco, J., Gil, S. M., ... Irazusta, J. (2016). Basketball performance is related to maturity and relative age in elite adolescent players. Journal of Strength and Conditioning Research, 30(5), 1325-1332.

Trninić, S., \& Dizdar, D. (2000). System of the performance evaluation criteria weighted per positions in the basketball game. Collegium antropologicum, 24(1), 217-234.
Vaeyens, R., Lenoir, M., Williams, A., \& Philippaerts, R. (2008). Talent identification and development programms in sport: Current models and future directions. Sports Medicine, 38, 703-714.

Vernillo, G., Silvestri, A., \& La-Torre, A. (2012). The Yo-Yo intermittent recovery test in junior basketball players according to performance level and age group. Journal of Strength and Conditioning Research, 26 (9), 2490-2494. 